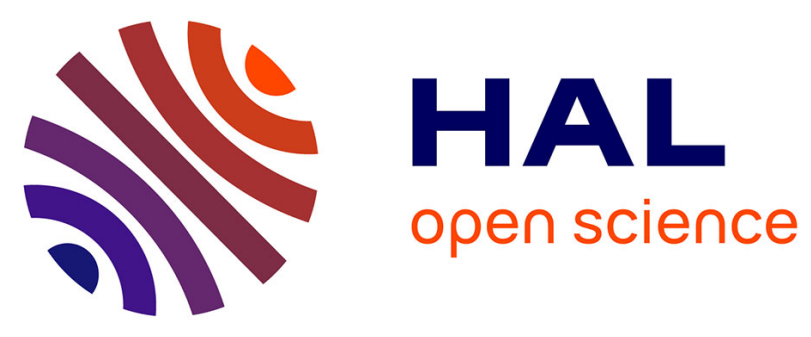

\title{
Horizontal Integration in Fresh Food Supply Chain
}

Flemming Christensen, Soujanya Mantravadi, Iskra Dukovska-Popovska, Hans-Henrik Hvolby, Kenn Steger-Jensen, Charles Møller

\section{To cite this version:}

Flemming Christensen, Soujanya Mantravadi, Iskra Dukovska-Popovska, Hans-Henrik Hvolby, Kenn Steger-Jensen, et al.. Horizontal Integration in Fresh Food Supply Chain. IFIP International Conference on Advances in Production Management Systems (APMS), Sep 2019, Austin, TX, United States. pp.164-172, 10.1007/978-3-030-30000-5_22 . hal-02419213

\section{HAL Id: hal-02419213 \\ https://hal.inria.fr/hal-02419213}

Submitted on 19 Dec 2019

HAL is a multi-disciplinary open access archive for the deposit and dissemination of scientific research documents, whether they are published or not. The documents may come from teaching and research institutions in France or abroad, or from public or private research centers.
L'archive ouverte pluridisciplinaire HAL, est destinée au dépôt et à la diffusion de documents scientifiques de niveau recherche, publiés ou non, émanant des établissements d'enseignement et de recherche français ou étrangers, des laboratoires publics ou privés. 


\title{
Horizontal Integration in Fresh Food Supply Chain
}

\author{
Flemming M. M. Christensen ${ }^{1}{ }^{凶}$, Soujanya Mantravadi ${ }^{2}$, Iskra Dukovska-Popovska ${ }^{1}$, \\ Hans-Henrik Hvolby ${ }^{1}$, Kenn Steger-Jensen ${ }^{1} \&$ Charles Møller ${ }^{2}$ \\ ${ }^{1}$ Centre for Logistics (CELOG), Materials \& Production, Aalborg University, Denmark \\ ${ }^{2}$ Centre for Industrial Production (CIP), Materials \& Production, Aalborg University, Denmark \\ fmmcam-tech.aau.dk
}

\begin{abstract}
Demand information sharing during planning and control of fresh meat production and replenishment in franchise supply chain is studied. Main findings are that some demand information is received much later upstream than when created downstream. Horizontal integration of systems in the supply chain allows all parties access to same critical information about store demand and availability in real-time. A conceptual model for horizontal integration in the triadic supply chain, allowing differentiated and timely sharing of information is suggested, to increase service level and reduce waste from over-/under-production.
\end{abstract}

Keywords: Retail supply chain · Integration $\cdot$ Real-time information sharing Fresh food products $\cdot$ MES

\section{Introduction}

In retail supply chains, information sharing $[1,2]$ is a large part of collaborative materials management (CMM) [3]. Sharing e.g. demand information allows transparency and visibility of product sales and availability in the supply chain. However, demand information is usually adjusted and aggregated downstream into orders before being shared, and is sent in batches at specified times or when manually initiating a transfer (e.g. sending purchase orders). It is often shared in dyadic structures via business level systems alike enterprise resource planning systems (ERP). Hence, supplier, wholesaler and retail stores plan (and schedule) and control their productions independently based on (adjusted) historical rather than real-time information and internal plans cf. internal setup $[4,5]$. Once scheduled, the production is frozen certain time into the future to reduce nervousness [4]. Albeit incremental planning is possible, options for changes continuously decrease, until finally impossible when production ends [4].

This is challenging when dealing with fresh food products. They need intensified and increased information sharing [6] during planning and control of production and replenishments, due to high demand variability and short shelf life [7]. Fresh meat products (FMPs) such as e.g. ground beef/pork/chicken/fish and ready-made meals are processed down to few hours before shipment to wholesaler; even while stores still send orders to wholesaler. Thus, sharing demand information longer time in advance of production start both increases demand uncertainty (cf.forecast) and reduces the supply chain responsiveness to unforeseen changes in demand. Even if possible, responses are costly and labor-intensive non-systemized exceptions management (through phone

adfa, p. 1, 2011.

(C) Springer-Verlag Berlin Heidelberg 2011 
calls and emails). Instead, sharing centrally managed demand information [8] in realtime allows common understanding of demand, effective instant decision-making, reduced risks and greater forecast accuracy [9]. To not put more pressure on business level systems, interest is in horizontal integration of planning and control systems online/in the sky to share real-time. In addition, for franchise, all decision-making is decentralized to stores, as opposed to corporate retail chains. It is thus relevant to also investigate how a triadic supply chain (supplier, wholesaler and retail stores) seamlessly can share real-time demand information horizontally during planning and control.

We analyze and identify issues in information sharing during fresh meat production and replenishment planning and control in franchise retail supply chain. A conceptual model is proposed to integrate systems in the supply chain with real-time demand information sharing along suggestions for which information to share. Following presents theoretical framework, methodology, case analysis, framework and conclusion.

\section{Theoretical Background}

Collaborative materials management $(\mathrm{CMM})$ is "operational planning and control of inventory replenishments in supply chains" [3]. Information sharing is a major part of CMM and governs the "capturing and dissemination of timely and relevant information for decision makers to plan and control supply chain operations" [2]. Especially demand information sharing influences CMM with direct impact on the planning and control effectiveness and waste from out-of-stock/oversupply situations [10-12].

In CMM there is differently increasing demand information sharing depending on the level of collaboration $[8,13,14]$. As example, in "vendor-managed inventory" (VMI) supplier may obtain full view of both historical demand, point-of-sales and inventory levels at wholesaler or retail stores (depending on whose inventory is managed). However, it only covers a dyadic supply chain limiting the efficient information sharing across entire (i.e. triadic) supply chain. Further, demand information sharing is through batch transactions from ERP or online access to ERP [13], causing redundant use of and pressure on ERP systems compared to if sharing directly between the systems where the information is created. The "collaborative planning, forecasting and replenishment" (CPFR) (VICS, 2014) includes demand exceptions and extends VMI with collaborative validation and synchronization of planning (incl. forecasting) by increasing demand information sharing. Yet, although information sharing is through special data transfer interfaces (e.g. EDI) [15] or even online applications for real-time/near real-time [16], it is still through ERP in a dyadic supplier-wholesaler relationship. Similarly for "process of collaborative store ordering" - although information sharing is through an online platform to enhance real-time demand sharing [14] it is dyadic between supplier and retail stores, i.e. without wholesaler' knowledge to and about demand information [8]. No CMM program entails real-time based triadic demand information sharing via planning and control systems to ensure complete (supply chain) demand visibility and efficient use of systems. Namely for supplier' manufacturing execution systems, wholesaler' warehouse management system and retail stores' cash register. For fresh food products with short shelf life there is stronger correlation between 
supply chain performance and level of information sharing, than long shelf life products [6]. Yet, although information sharing generally improves supply chain performance [17], responsiveness [18] and freshness of products [7], research also suggest that the level of improvement is not per se always positive as sharing too much/irrelevant information may decrease performance and "result in an expected loss" [19]. In turn, information sharing (and thus also collaboration) depends on factors such as e.g. specific demand situation $[12,20]$, type of product [6] as well as type of information shared, with whom it is shared and how it is shared [21].

From the production perspective, the concept of inter-enterprise integration and the supplier's involvement in the supply chain using information systems is not new. Level 3 systems as per ISA 95 standard set by 'International society of automation' also address the need for systems to interconnect, to provide value to the manufacturing enterprises and beyond. Enterprise systems are known to enhance the collaboration between the supplier and the end user by reducing transaction costs [22]. Since MES/MOM systems are real-time compliant, it becomes advantageous for fresh food supply chains to access the product centric data via factory control systems [23]. Supplier can thus play an important role in improving the supply network design as problems related to bullwhip tend to impact all chain parties.

There are various approaches to interenterprise integration based on the need for information sharing. Owing to that, information exchange via web based MES/MOM systems can follow several classes of information interfaces such as: SCOR, CPFR, RosettaNet for process data; EDIFACT for structured data; and TCP/IP reference model \& basic internet services for unstructured data [24]. Supplier and buyer integration in a supply chain for collaborative materials planning is a known method in the operations management. But the collaborative approach by integrating shop floor level systems is not well understood in theory. Over the last two decades, ERP systems have evolved from being monolithic to modular ERP II systems by extending into the supply chains [25]. Similarly, the scope of MES/MOM systems could also be extended into supply chains, for which we present web-based service-oriented architecture (SOA) as a suitable approach for horizontal integration. Modularity and remote access via internet technology are key reasons for considering service-oriented MES/MOM systems.

\section{$3 \quad$ Methodology}

After investigating demand information sharing in the supply chain and where different demand information is created, the purpose is to propose a conceptual model for realtime sharing through horizontal integration of planning and control systems. This, to ensure all parties access to same critical information about store demand and availability in real-time. The focus is on FMPs and ensuring decentralized order decision-making cf. franchise retailing. The goal is to ensure complete transparency of demand (i.e. store sales) and inventories across the supply chain in real-time, allowing live production scheduling at supplier. The case is studied in natural context to ensure enriched understanding and insight [26] as both context and product type is critical. To provide a generalizable view, focus is on beef, pork, chicken and fish with total shelf-life of 8 
days or less which are produced short time before delivery to wholesaler. The supply chain is triadic, i.e. supplier, wholesaler and retail stores (franchisors) with retail chain (franchisee). Wholesaler is one of the largest grocery wholesalers in Denmark and supplies 328 franchise stores with FMPs from five suppliers each day through a central warehouse, via two replenishment cycles: supplier-wholesaler and wholesaler-store. The past year stores have ordered 10 to 47 SKUs each day; 4-25 beef incl. veal and cattle, 1-16 pork, 1-9 chicken and 1-4 fish; depending on season/campaigns. All FMPs are shipped from supplier, consolidated at wholesaler and delivered to stores. Waste levels in stores from theft and expiration are considered very low $(<1 \%$, estimated) but included in the calculation of inventory levels. Information and data are obtained via semi-structured interviews with IT-manager, purchaser and purchasing manager (wholesaler), purchasing assistant (retail chain), personnel (retail stores) and, sales manager, production planner and vice president (supplier), from standardized questions about planning/scheduling/control processes.

\section{Information Sharing in Fresh Meat Supply Chain}

First, wholesaler creates an order in the purchase planning system (PPS) and sends it to supplier via ERP by latest 16:00 (day 1). After confirmation (via ERP), supplier schedules the order for production during the night/following morning and deliver to wholesaler between 06:00 and 13:00 (day 2). While the production still runs (supplier) and FMPs are received (wholesaler), stores create orders in their ERP via hand-terminals and send to retail chains' ERP at latest by 11:00 (day 2). The store orders are then transferred to wholesaler' ERP and further to the warehouse management system (WMS), releasing orders for picking from 14:00 in two batches (dependent on delivery times to stores). The FMPs are physically delivered to the stores between 18:00 (day 2) and 05:00 (day 3). This results in a lead-time of down to 14 hours for wholesaler, and down to 7 hours for stores, from sending store order until received. Figure 1 depicts where the demand information is created and available, grouped vertically by supply chain stage and type of demand information (see 1/2/3 in figure). White boxes, except "R Studio" (forecasting), are real-time information systems and the grey are ERP.

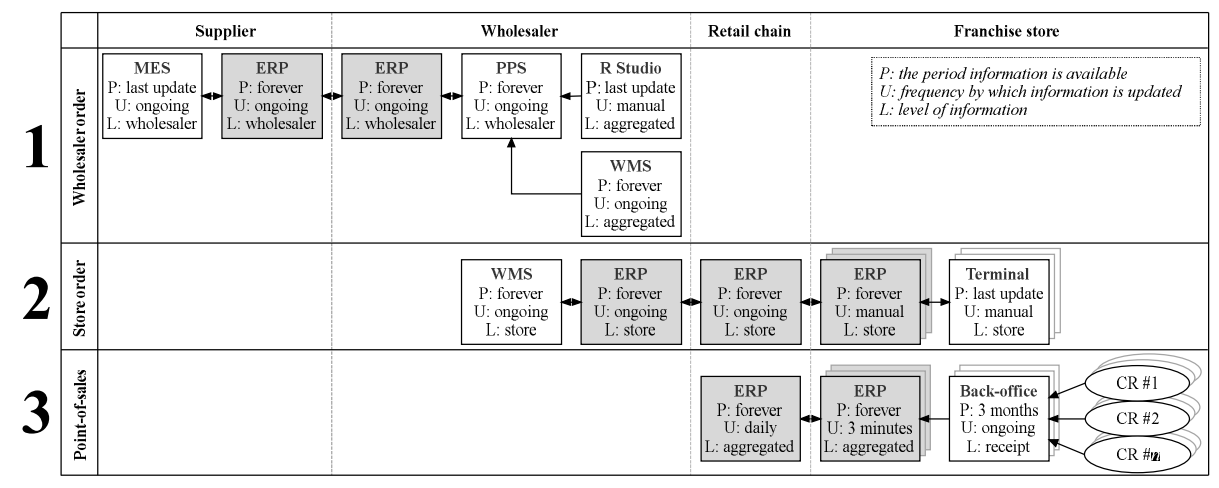

Fig. 1. Order-information creation and storing in systems 
Creation of Wholesaler Orders (1) and Transfer to Supplier (Cycle 1). Wholesaler forecasts total store demand (via R Studio) at daily level considering weekday-patterns. Based on this, inventory levels (from WMS) and yesterday' store demand (from ERP), wholesaler estimates the following day' demand. Although (aggregated) POS from yesterday' sale in stores can be accessed, is not used since logging on retail chain' ERP and looking up each product' sale in stores is rather time-consuming. When order quantity is set (i.e. expected demand minus incoming pre-orders and inventory), the order is loaded into wholesaler' ERP. The purchaser manually sends the order to the supplier through EDI-FACT, awaiting an order confirmation. In Figure 1, from right to left.

Creation of Store Orders (2) and Transfer to Wholesaler (Cycle 2). When stores order products, personnel walk around in the store and scan shelf labels with a handheld terminal as seem needed, i.e. less available than desired. The personnel can see usual sales the given weekday (manually uploaded to the terminal from ERP before starting the ordering process). Quantity is determined from what pre-determined amount to be available minus actual available amount in boxes - and adjusted for sales the following day if it is expected to increase. When the order is final, it is transferred from to the ERP. For each product, the personnel see what is usually sold at surrounding days, general historical sale, campaign information (last/current) and how much is in preorder. When adjusted the order is sent to retail chain' ERP, and then to wholesaler' ERP and from here further to the WMS for picking. In Figure 1, from right to left.

Creation of POS (3) and its Transfer across Supply Chain. POS is created and registered at an individual local database at each CR in each store (app. 1,100 for entire chain). Every three minutes, the POS is sent the store' back-office database, where it is consolidated with POS from the other 2-3 CRs in the store. This receipt-level POS is saved for three months and constantly deleted as time pass by, due to storage limitations. From here, the receipt POS is transferred to the ERP' database in each store which constantly aggregates with latest POS (aggPOS) cf. 3 minutes transfer interval. Here all sales data is saved on a native database, and this is the first time the store, retail chain and wholesaler can manually log on and access aggPOS data older than 3 months. Around midnight all aggPOS (amount per SKU per price per day) from all stores is transferred to the retail chain' database. From around 6-7 in the morning, procurement at retail chain can readily access the aggPOS in their ERP. Logging on to retail chain' ERP, wholesaler may also access the information. In Figure 1, from right to left.

To sum up, one of the main-findings is that the true demand (POS) is aggregated and only available in certain systems in batches and from certain time-points. This cause unstructured manual exceptions management (by phone) and reduces the ability to immediately react to changes in demand in stores. Further, wholesaler decides order quantity on two days' old demand-data influenced by 328 different stores' decision-making rather than real sales. This, albeit different information is available at different supply chain stages in real-time, hereunder demand at cash register (CR) in stores (i.e. point of sale (POS)), inventory levels at wholesaler and production status at supplier. Another main-finding is the time it takes to transfer and save aggPOS from stores to wholesaler 
through ERP - and the consequent delay before being available for decision-making. Since supplier produces FMPs down to hours before shipment, decreasing transfer time and sharing information directly between relevant systems (CR, WMS and MES) will increase the ability to react to demand changes. Further to this, retail stores manually control amounts of products available when determining order size, albeit having a predetermined max-amount of each product. Given the low level of theft and waste (cf. close-to-expiration products sold at reduced price), inventory levels may be derived from ordered quantities subtracted POS with only weekly/periodic check. And chosen max-amounts may even further be evaluated cf. amount of products sold at reduced price is registered in POS.

\section{$5 \quad$ Proposed Framework for Real-Time Information Sharing through Horizontal Integration}

Not only does current systems integration make actual demand rather opaque, it also increases the risk of bullwhip effect. In literature, sharing of POS is argued as having positive impact on the supply chain performance, and a necessity for collaborative materials management $[8,13,14]$. To allow timely information sharing Figure 2 illustrates a conceptual model for integration of systems via horizontal integration, allowing decision-making based on real-time information sharing. Given wholesaler' role in the supply chain [5], the model assumes wholesaler to be coordinator of information and product flows. Information about demand (i.e. POS) and derived inventories from stores, production execution and status (i.e. MES) from supplier as well as inventories at wholesaler is shared in real-time.

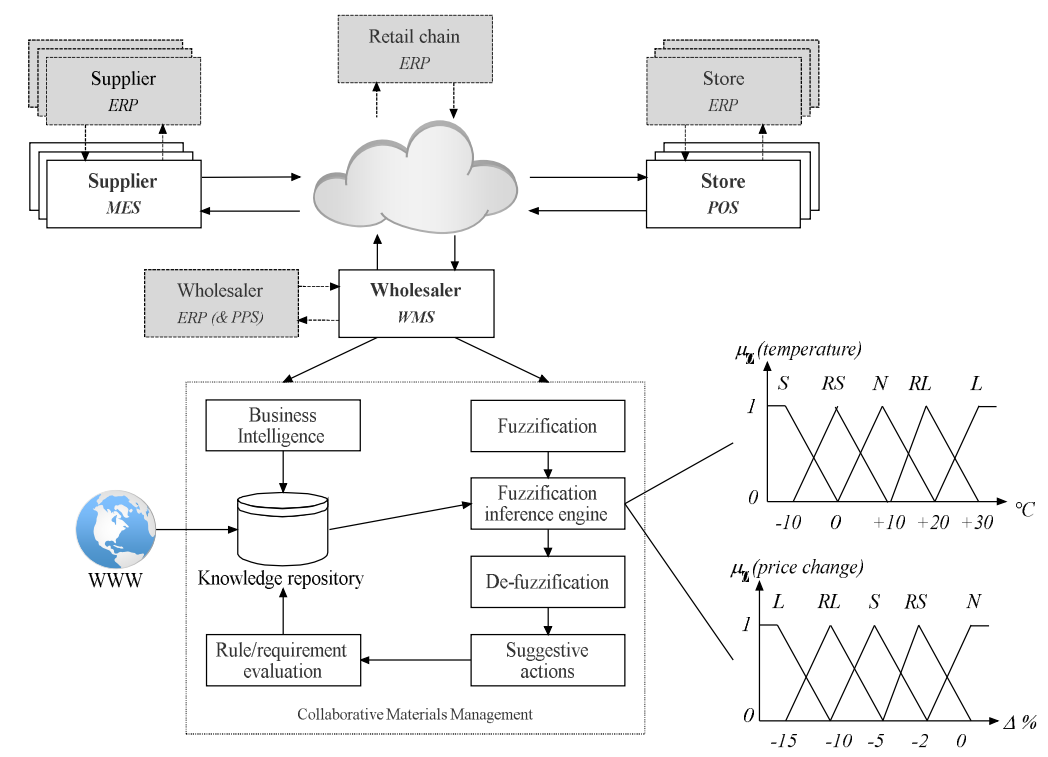

Fig. 2. Real-Time Information Sharing through Horizontal Integration 
Based on this information, and (by store) pre-determined max-amounts in each store, wholesaler applies an ongoing fuzzification-process which is based on a knowledge repository (retrieving information from the web and business intelligence) and inference engine. E.g. if weather is expected to increase, then the derived expected consequence on demand is included in the suggestive actions. From this, the system will constantly evaluate ongoing demand and changes in demand (POS) against chances for changing already sent demand information to suppliers - filtered according to how far supplier is in production schedule.

If demand in stores sudden deviates, an alarm will occur informing the system about potential need for additional products (and vice versa, if no sale happens). Then, based on supplier' production status, the system will inform MES about additional/fewer quantities to be produced. Products which can be changed constantly follow open production orders in real-time. Thus if production of product A just finished, product A cannot be subject for any alteration. The further into the future the production is, the greater allowance for quantity changes. In this way systems across supplier (i.e. MES), wholesaler (i.e. WMS) and store (i.e. POS) will integrate horizontally, eliminating transfer through ERP. By allowing for "blanket" orders, the MES, WMS and CR will inform ERP about workload, opposite today, where ERP informs about workload. For reasons of speed, web-based information transfer is suggested.

\section{Conclusion \& Future Research Directions}

The FMP production at suppliers is scheduled certain time after wholesaler sends order based on adjusted demand (i.e. wholesale order), despite actual sales is still recorded in stores - and it still runs while actual store orders are sent. No integration of planning and control systems challenges the timely information sharing $[1,2]$ with centrally adjusted demand [8]. By integrating the planning and control systems where demand information is created (MES, WMS and POS) across the supply chain then e.g. sudden changes to demand may be shared (near) live. Whether increase or decrease in demand it allows the entire triadic supply chain to react instantly and respond accordingly. This is particularly crucial for products processed each day e.g. ground beef/chicken/fish.

This research has focused on major common FMP-types in grocery industry in a conceptual model. More research is needed for other FMP-types to establish the validity in sharing POS in real-time and define what supply chain characteristics must be in place - when comparing against FMP with long shelf life. Also, the framework should be tested out empirically to investigate and quantify impact on service level across the supply chain, as well as ability to meet sudden changes in demand. The focus is regular demand, hence to test the generalizability, it would be favourable to test the model in different types of demand such as campaign, product introduction or seasonal demand. Also, this study has focused on franchise retail stores with decentralized decision-making. Additional research is needed for other store-types where centralized decisionmaking may be used such as corporate retail chain. 


\section{References}

1. Simatupang, T.M., Sridharan, R.: An Integrative Framework for Supply Chain Collaboration. Int. J. Logist. Manag. 16, 257-274 (2005).

2. Simatupang, T.M., Sridharan, R.: The Collaboration Index: a Measure for Supply Chain Collaboration. Int. J. Phys. Distrib. Logist. Manag. 35, 44-62 (2005).

3. Jonsson, P., Holmström, J.: Future of Supply Chain Planning: Closing the Gaps Between Practice and Promise. Int. J. Phys. Distrib. Logist. Manag. 46, 62-81 (2016).

4. $\quad$ Fleischmann, B., Meyr, H., Wagner, M.: Advanced Planning \& Structure of Advanced Planning Systems. In: Stadtler, H., Kilger, C., and Meyr, H. (eds.) Supply Chain Management and Advanced Planning. pp. 81-106. Springer Berlin Heidelberg, New York (2015).

5. Hübner, A.H., Kuhn, H., Sternbeck, M.G.: Demand and Supply Chain Planning in Grocery Retail: an Operations Planning Framework. Int. J. Retail Distrib. Manag. 41, 512-530 (2013).

6. Lusiantoro, L., Yates, N., Mena, C., Varga, L.: A Refined Framework of Information Sharing in Perishable Product Supply Chains. (2018).

7. Ferguson, M.E., Ketzenberg, M.E.: Information Sharing to Improve Retail Product Freshness of Perishables. Prod. Oper. Manag. 15, 57-73 (2006).

8. Alftan, A., Kaipia, R., Loikkanen, L., Sepns, K.: Centralised Grocery Supply Chain Planning: Improved Exception Management. Int. J. Phys. Distrib. Logist. Manag. 45, 237-259 (2015).

9. Swaminathan, J.M., Tayur, S.R.: Models for Supply Chains in E-Business. Manage. Sci. 49, $1387-$ $1406(2003)$.

10. Ettouzani, Y., Yates, N., Mena, C.: Examining Retail On Shelf Availability: Promotional Impact and a Call for Research. Int. J. Phys. Distrib. Logist. Manag. 42, 213-243 (2012).

11. Alfalla-Luque, R., Medina-Lopez, C., Dey, P.K.: Supply Chain Integration Framework Using Literature Review. Prod. Plan. Control. 24, 800-817 (2013).

12. Adebanjo, D.: Understanding Demand Management Challenges in Intermediary Food Trading: A Case Study. Supply Chain Manag. An Int. J. 14, 224-233 (2009).

13. Ståhl Elvander, M., Sarpola, S., Mattsson, S.: Framework for Characterizing the Design of VMI Systems. Int. J. Phys. Distrib. Logist. Manag. 37, 782-798 (2007).

14. Pramatari, K., Miliotis, P.: The Impact of Collaborative Store Ordering on Shelf Availability. Supply Chain Manag. An Int. J. 13, 49-61 (2008).

15. Danese, P.: Collaboration Forms, Information and Communication Technologies, and Coordination Mechanisms in CPFR. Int. J. Prod. Res. 44, 3207-3226 (2006).

16. Whipple, J.M., Russell, D.: Building Supply Chain Collaboration: a Typology of Collaborative Approaches. Int. J. Logist. Manag. 18, 174-196 (2007).

17. Cui, R., Allon, G., Bassamboo, A., Van Mieghem, J.A.: Information Sharing in Supply Chains: An Empirical and Theoretical Valuation. Manage. Sci. 61, 2803-2824 (2015).

18. Thatte, A.A., Rao, S.S., Ragu-Nathan, T.S.: Impact of SCM Practices of a Firm on Supply Chain Responsiveness and Competitive Advantage of a Firm. J. Appl. Bus. Res. 29, 499-530 (2012).

19. Choi, T.M., Li, J., Wei, Y.: Will a supplier benefit from sharing good information with a retailer? Decis. Support Syst. 56, 131-139 (2013).

20. Jonsson, P., Mattsson, S.-A.: The Value of Sharing Planning Information in Supply Chains. Int. J. Phys. Distrib. Logist. Manag. 43, 282-299 (2013).

21. Kumar, R.S., Pugazhendhi, S.: Information Sharing in Supply Chains: An Overview. Procedia Eng. 38, 2147-2154 (2012).

22. J.M., T., D.C., Y., M., B.: Exploring the Rationales for ERP and SCM Integration. Ind. Manag. Data Syst. 102, 26-34 (2002).

23. Mantravadi, S., Møller, C., Christensen, F.M.M.: Perspectives on Real-Time Information Sharing through Smart Factories: Visibility via Enterprise Integration. In: International Conference on Smart Systems and Technologies (SST): IEEE Region 8, Croatian Academy of Engineering. pp. 133-137 (2018).

24. Scheer, C., Theling, T., Loos, P.: Information Interface Classification of Actors in Supply Chains. Eighth Am. Conf. Inf. Syst. 36-40 (2002).

25. Møller, C.: ERP II: A Conceptual Framework for Next-Generation Enterprise Systems? J. Enterp. Inf. Manag. 18, 483-497 (2005).

26. Eisenhardt, K.M.: Building Theories from Case Study Research. Acad. Manag. Rev. 14, 532-550 (1989). 